\title{
Alliance formation of Indo-Pacific bottlenose dolphins (Tursiops aduncus) off Amakusa, western Kyushu, Japan
}

\author{
Miki Nishita ${ }^{1, *}$, Miki Shirakihara ${ }^{2}$, Naoko Iwasa ${ }^{1}$ and Masao Amano ${ }^{1}$ \\ ${ }^{1}$ Graduate School of Fisheries and Environment Sciences, Nagasaki University, 1-14 Bunkyo-machi, Nagasaki 852-8521, Japan \\ ${ }^{2}$ Faculty of Science, Toho University, 2-2-1 Miyama, Funabashi, Chiba 274-8510, Japan
}

\begin{abstract}
Indo-Pacific bottlenose dolphins (Tursiops aduncus) off Amakusa-Shimoshima, approximately 200 individuals, form relatively large groups frequently exceeding 100 individuals and show high site fidelity to the area around Tsuji Island, northern coast of Amakusa-Shimoshima. This suggests that individual dolphins may have long interaction times with many other individuals. Consequently, competition between males is likely to be high and formation of alliances may be expected. However, this has not yet been confirmed. With photo-identification data collected between 2010 and 2014, we examined individual associations. Pairs of males formed significantly non-random associations for multiple years, and were seen surrounding females, many of whom were considered to be receptive at that time. Our results suggest that male Indo-Pacific bottlenose dolphins form alliances in this population, where dolphins form large groups and show high site-fidelity.
\end{abstract}

Key words: association, social strategy.

Cooperative behavior to gain access to a receptive female is unusual because fertilizations are non-shareable (Watts 1998). However, males of some species form cooperative stable relationships to gain access to or defend females, or to increase social rank (Goodall 1986; Packer et al. 1991; Connor et al. 1996). These cooperative relationships between males are called alliances or coalitions. The formation of alliances is regarded as one of the most socially complex male mating strategies in mammals (Wiszniewski et al. 2012).

The prevalence and complexity of these cooperative relationships, however, varies considerably among species as well as within and between populations depending on ecological and social environments (Wiszniewski et al. 2012). While there are some populations where dolphins are considered to not form alliances (bottlenose dolphins, Tursiops truncatus, in Moray Firth, Scotland, Wilson 1995; in Doubtful Sound in New Zealand, Lusseau 2007), some studies on bottlenose dolphins (Tursiops spp., in Shark Bay, Australia, Connor et al. 1992, 2001; Connor and Krützen 2015) and Atlantic spotted dolphins (Stenella frontalis, in the Bahamas, Elliser and Herzing 2014) have reported the complex formation of alliances.

To make sense of the variation in the likelihood of males forming alliances between and within populations, Whitehead and Connor (2005) examined the ecological basis for the formation of alliances. Their modeling demonstrated that the likelihood of males forming alliances was affected by the mean number of males competing for a female. This number is approximately the product of resource utilization time and the rate at which resources are encountered by males (Connor and Whitehead 2005). As encounter rate increases, the mean number of males competing for a female becomes higher and males are thought to form alliances but there are not many reports confirming the alliance formation in such situations, and the ecological basis for the alliance formation has not been well examined.

Approximately 200 Indo-Pacific bottlenose dolphins (T. aduncus) are seen off Amakusa-Shimoshima, and dolphins in this population demonstrate high site-fidelity for the area around Tsuji Island located in the northern coast of Amakusa-Shimoshima, western Kyushu, Japan (Inoue et al. 2017; Fig. 1) and form relatively large groups exceeding 100 individuals (Shirakihara et al. 2002). When group size is large, number of groups will be fewer, and thus males will have longer travel times between groups, which will promote longer residence of

*To whom correspondence should be addressed.E-mail: miki.nishita@gmail.com 
males (Whitehead 1990, 1998). Under such circumstances, males may face increased competition with a higher number of other males because high site-fidelity and large group size indicate that dolphins spend longer time with many other individuals. Therefore, encounter rate and thus, the mean number of males competing for a female in Amakusa-Shimoshima population is thought to be higher than other previously studied populations, where bottlenose dolphins form smaller groups and show typical fission-fusion societies (e.g., $\bar{x}=4.8$ in Shark Bay, Smolker et al. $1992 ; \bar{x}=7$ in Sarasota Bay, Scott et al. $1990 ; \bar{x}=15$ in the Gulf of California, Balance 1990; $\bar{x}=$ 3.45 in the Bahamas, Rogers et al. 2004). In this study, we examined whether male dolphins form alliances in the northern coast of Amakusa-Shimoshima where the number of males competing for receptive females is thought to be larger than other populations owing to a high sitefidelity and large group size.

\section{Materials and methods}

\section{Data collections}

Commercial dolphin-watching tours are conducted regularly in the study area (Inoue et al. 2017). The dolphin-watching tour boats (most of them approximately ten meters in length) depart at Futae Port on the northern coast of Amakusa-Shimoshima, western Kyushu, Japan (Fig. 1), and one to five 'one-hour cruise' are conducted in a day throughout the year. Photo- identification sampling sessions were conducted by using these commercial dolphin-watching tour boats between 2010 and 2014. One-hour sampling trip represented one cruise from departure to arrival at the port. The dorsal fins of dolphins around the boat were photographed using a digital camera (CANON EOS Kiss x3, Canon EOS 40D, or Canon EOS 7D) with a 75- to 300$\mathrm{mm}$ zoom lens. Photographs were randomly collected by focusing on an individual that is close to our boat one by one as many as we can. Photographs in which more than one individual were photographed were used for the detection of alliances. For each dorsal fin in the photographs, the photo quality (focus, contrast, relative size of the dorsal fin to the frame size, and visibility of the entire dorsal fin) was evaluated and only photographs of the dorsal fins with sufficiently high photoquality were used for analyses. The sex of dolphins was determined on the basis of the presence of calves in photo-identification data collected between 1994 and 2013: individuals repeatedly observed accompanied by relatively smaller dolphins presumed to be their calves were regarded as females, and individuals that have never been observed accompanied by smaller dolphins for ten years were regarded as males (Van Bressem et al. 2013). All of the procedures performed involving animals were in accordance with the ethical standards of the Institutional Animal Care and Use Committee of Nagasaki University, Japan (approval number 1506181239).

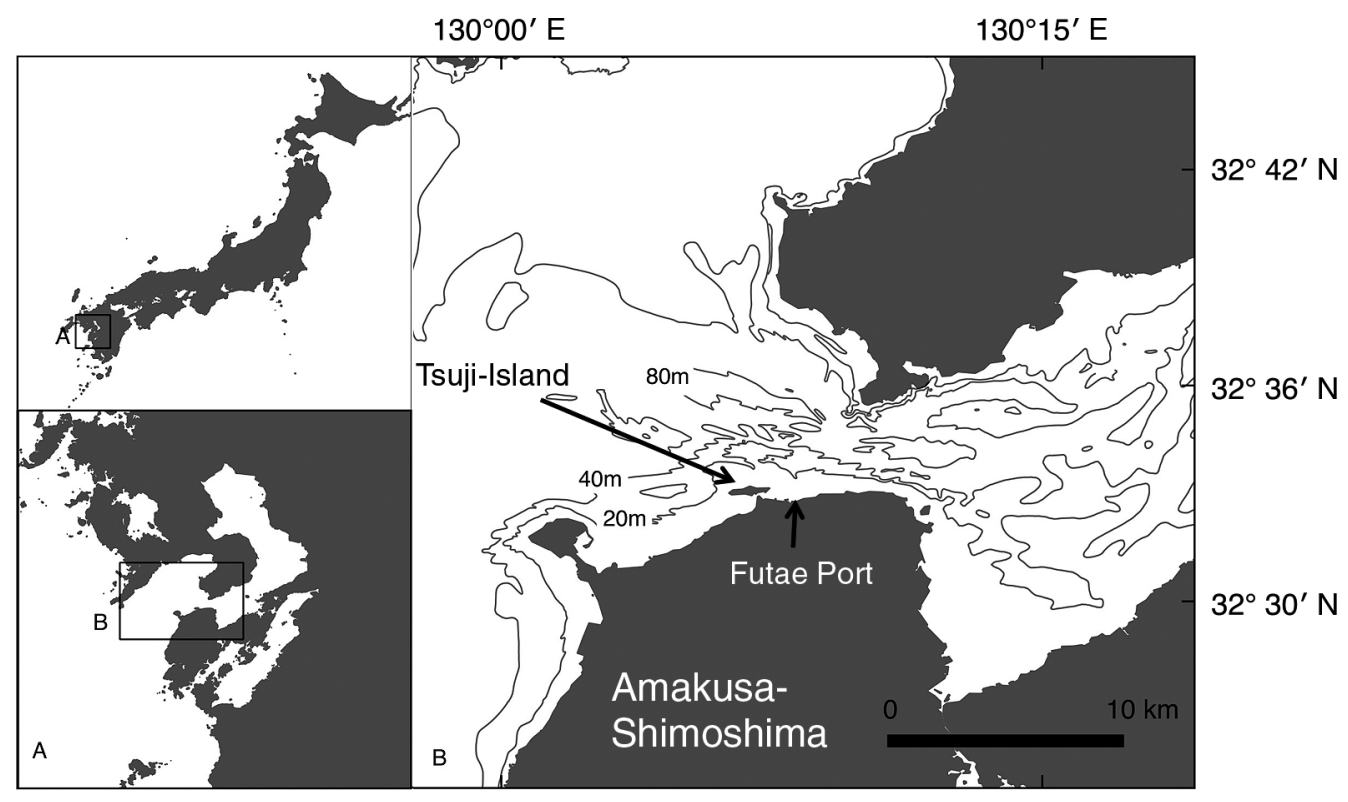

Fig. 1. Study area around Amakusa-Shimoshima, western Kyushu, Japan. 
Table 1. Number of survey days, males, and images in which multiple males were photo-captured, and mean and coefficient of variation $(\mathrm{CV})$ of observed and randomly estimated half-weight indices (HWIs)

\begin{tabular}{|c|c|c|c|c|c|c|c|c|}
\hline \multirow{2}{*}{ Year } & \multirow{2}{*}{ Survey days } & \multirow{2}{*}{ Number of males } & \multirow{2}{*}{$\begin{array}{l}\text { Number of images in } \\
\text { which multiple males } \\
\text { were photo-captured }\end{array}$} & \multicolumn{2}{|c|}{ Mean of HWIs } & \multicolumn{2}{|c|}{$C V$ of HWIs } & \multirow{2}{*}{$P$-value } \\
\hline & & & & Observed & Random & Observed & Random & \\
\hline 2010 & 23 & 31 & 365 & 0.03140 & 0.03140 & 1.90308 & 1.39576 & 0.0005 \\
\hline 2011 & 30 & 20 & 256 & 0.04031 & 0.04031 & 1.46466 & 1.07105 & $<0.0001$ \\
\hline 2012 & 32 & 31 & 896 & 0.04930 & 0.04920 & 1.43859 & 0.95072 & $<0.0001$ \\
\hline 2013 & 35 & 12 & 242 & 0.07497 & 0.07483 & 1.14924 & 0.66936 & $<0.0001$ \\
\hline 2014 & 31 & 19 & 368 & 0.05547 & 0.05545 & 1.53099 & 1.00046 & $<0.0001$ \\
\hline
\end{tabular}

$P$-values are from permutation tests for differences in $\mathrm{CV}$ between observed and random HWIs.

\section{Data analyses}

Alliances are recognizable by their constant association, side-by-side travel formation and synchronous surfacing (Connor et al. 2001). In Amakusa-Shimoshima population, it is difficult to follow and describe some specific dolphins' behavior in a large group of 100 individuals. Therefore, individuals photo-captured on the same photograph, within approximately three body lengths from one another were defined as associated. The sampling period was set to daily, and half-weight association indices (HWIs) were calculated (Cairns and Schwager 1987). Permutation tests for non-random associations were conducted using the annual dataset for males that identified throughout the year. In the permutation test, the coefficient of variation $(\mathrm{CV})$ of the observed HWI was compared with that of the randomized HWI calculated from 20000 permutations with 100 flips per permutation.

Possible alliance members were identified according to the following association criteria: (1) significantly non-random associations defined by emerging every time across ten permutation tests for multiple years; (2) reciprocally the best associates; (3) higher associations compared with the mean of the maximum HWI among males, following Möller et al. (2001).

For the image in which possible alliance members were photographed, we investigated whether they jointly surrounded a female in that image. The reproductive states of females were categorized based on the presence of calves and their age estimated based on their sighting histories collected until 2015. Because the minimum calving interval for mothers that succeeded in bringing a calf to weaning age was three years (Kogi et al. 2004), females with a calf whose age is more than two year of age were presumed to be receptive at that time. Females who gave birth in the following year were also presumed to be receptive at that time. However, female who gave birth within ten months from the observation with the possible
Table 2. Half-weight association indices (HWIs) between male pairs that have significantly higher HWI in multiple years and the mean maximum HWIs of males

\begin{tabular}{ccccccc}
\hline & Pair & 2010 & 2011 & 2012 & 2013 & 2014 \\
\hline A & $\# 0030, \# 0172$ & $\mathbf{0 . 4 4}$ & $\mathbf{0 . 3 3}$ & $\mathbf{0 . 3 6}$ & - & - \\
B & $\# 0117, \# 0120$ & $\mathbf{0 . 5 3}$ & - & $\mathbf{0 . 2 0}$ & - & $\mathbf{0 . 4 9}$ \\
C & $\# 0039, \# 0129$ & $\mathbf{0 . 3 2}$ & - & $\mathbf{0 . 4 7}$ & - & $\mathbf{0 . 5 8}$ \\
D & $\# 0083, \# 0149$ & 0 & $\mathbf{0 . 3 4}$ & $\mathbf{0 . 2 3}$ & - & $\mathbf{0 . 5 2}$ \\
E & $\# 0041, \# 0083$ & 0.16 & 0 & $\mathbf{0 . 3 5}$ & - & $\mathbf{0 . 2 4}$ \\
F & $\# 0022, \# 0023$ & $\mathbf{0 . 1 7}$ & 0 & $\mathbf{0 . 1 9}$ & 0.25 & 0.04 \\
G & $\# 0024, \# 0073$ & $\mathbf{0 . 2 3}$ & - & $\mathbf{0 . 3 0}$ & - & - \\
H & $\# 0073, \# 0193$ & 0.11 & $\mathbf{0 . 1 2}$ & 0.11 & $\mathbf{0 . 2 6}$ & 0.10 \\
I & $\# 0065, \# 0086$ & $\mathbf{0 . 5 3}$ & - & $\mathbf{0 . 6 7}$ & - & - \\
J & $\# 0076, \# 0208$ & $\mathbf{0 . 2 7}$ & 0.04 & $\mathbf{0 . 5 4}$ & - & - \\
\hline Mean of maximum & 0.23 & 0.21 & 0.30 & 0.26 & 0.29 \\
HWI $(S D)$ & $(0.15)$ & $(0.10)$ & $(0.16)$ & $(0.12)$ & $(0.19)$ \\
\hline
\end{tabular}

The significantly higher HWIs (shown in bold) were detected by permutation tests, in which they were compared with random HWIs calculated by 20000 permutations. The figures in italics indicate that the pair was reciprocal top associates. Hyphen indicates that each or both of the pair was not identified for a certain period of time in that year.

alliance members were considered to be pregnant.

All social analyses were conducted using SOCPROG 2.6 (Whitehead 2009).

\section{Results}

\section{Data collections}

A total of $>203000$ photographs were collected during 480 sampling sessions on 151 days (Table 1). Throughout the five-year study period, a total of 31 males were identified (Table 1). Of all 103631 images in which individuals were identified with enough quality, 22925 images (22.1\%) included two identified individuals, and 6006 images (5.8\%) included more than two identified individuals. On average, 1.35 individuals $(S D=$ $0.64)$ were identified in a single image. 
Table 3. List of cases in which the male pairs surrounded a female

\begin{tabular}{|c|c|c|c|c|c|c|}
\hline \multirow[b]{2}{*}{ Case } & \multirow[b]{2}{*}{ IDs } & \multirow[b]{2}{*}{ Date } & \multicolumn{4}{|c|}{ Females surrounded by the pair } \\
\hline & & & ID & Reproductive state & $\begin{array}{l}\text { Give birth in } \\
\text { the next year? }\end{array}$ & Receptive? \\
\hline A-1 & $\# 0030, \# 0172$ & 2010/8/9 10:10 & $\# 0135$ & $?$ & $?$ & $?$ \\
\hline A-2 & & 2010/9/19 10:25 & \#6011 & without calves & Yes & Yes \\
\hline B-1 & \#0117, \#0120 & $2010 / 5 / 916: 49$ & \#9906 & without calves & Yes & Yes \\
\hline B-2 & & $2010 / 5 / 3013: 36$ & \#9906 & without calves & Yes & Yes \\
\hline B-3 & & 2010/7/29 11:45 & $\# 0248$ & with a calf (age unknown) & No & $?$ \\
\hline B-4 & & 2010/8/10 11:58 & $\# 0248$ & with a calf (age unknown) & No & $?$ \\
\hline B-5 & & 2010/9/19 14:42 & $\# 0248$ & with a calf (age unknown) & No & $?$ \\
\hline B-6 & & 2013/9/30 14:05 & $\# 0050$ & $\begin{array}{l}\text { without calves and considered } \\
\text { to be pregnant }\end{array}$ & Yes & No \\
\hline B-7 & & $2014 / 2 / 2513: 39$ & \#9997 & with a calf ( $1-2$ yr old $)$ & Yes & Yes \\
\hline B-8 & & $2014 / 3 / 2712: 31$ & \#9997 & with a calf ( $1-2$ yr old $)$ & Yes & Yes \\
\hline D-1 & $\# 0083, \# 0149$ & 2014/7/20 10:44 & \#0107 & with a calf $(>2$ yr old $)$ & No & No \\
\hline D-2 & & $2011 / 7 / 2912: 13$ & $\# 0113$ & with a calf ( $1-3$ yr old $)$ & Yes & Yes \\
\hline D-3 & & $2012 / 7 / 2313: 58$ & $\# 0100$ & with a calf $(>2$ yr old $)$ & No & Yes \\
\hline E-1 & $\# 0041, \# 0083$ & 2014/1/17 11:39 & $\# 0100$ & with a calf $(>2$ yr old $)$ & No & Yes \\
\hline E-2 & & 2014/1/17 13:30 & $\# 0100$ & with a calf $(>2$ yr old $)$ & No & Yes \\
\hline G-1 & $\# 0024, \# 0073$ & $2010 / 5 / 3013: 26$ & $\# 6043$ & $?$ & Yes & Yes \\
\hline $\mathrm{H}-1$ & \#0073, \#0193 & 2013/7/18 10:34 & $\# 6030$ & with a calf $(<1 \mathrm{yr}$ old $)$ & No & No \\
\hline $\mathrm{H}-2$ & & 2014/1/23 11:47 & \#0177 & $\begin{array}{l}\text { with a calf ( }>2 \text { yr old }) \text { and } \\
\text { considered to be pregnant }\end{array}$ & No & No \\
\hline $\mathrm{I}-1$ & $\# 0065, \# 0086$ & $2010 / 5 / 3013: 48$ & \#0166 & $?$ & $?$ & $?$ \\
\hline $\mathrm{I}-2$ & & $2010 / 6 / 2012: 14$ & $\# 0166$ & $?$ & $?$ & $?$ \\
\hline $\mathrm{I}-3$ & & $2011 / 4 / 1610: 43$ & $\# 0050$ & without calves & Yes & Yes \\
\hline $\mathrm{I}-4$ & & $2012 / 5 / 2716: 38$ & \#0106 & with a calf ( $1-3 \mathrm{yr}$ old $)$ & No & No \\
\hline $\mathrm{I}-5$ & & 2012/8/9 11:57 & $\# 0040$ & without calves & No & Yes \\
\hline I-6 & & 2012/9/11 10:44 & $\# 0087$ & without calves & No & Yes \\
\hline $\mathrm{I}-7$ & & 2013/1/10 13:15 & $\# 0100$ & with a calf $(>2$ yr old $)$ & No & Yes \\
\hline $\mathrm{J}-1$ & \#0076, \#0208 & $2010 / 5 / 913: 15$ & $\# 6068$ & with a calf (age unknown) & No & No \\
\hline $\mathrm{J}-2$ & & $2010 / 6 / 2012: 10$ & $\# 0113$ & with a calf $(<2$ yr old $)$ & No & No \\
\hline $\mathrm{J}-3$ & & 2012/4/23 10:10 & $\# 6025$ & with a calf (age unknown) & Yes & Yes \\
\hline $\mathrm{J}-4$ & & $2012 / 5 / 23$ 15:04 & $\# 6025$ & with a calf (age unknown) & Yes & Yes \\
\hline $\mathrm{J}-5$ & & $2012 / 6 / 2511: 34$ & $\# 6025$ & with a calf $(>2$ yr old $)$ & Yes & Yes \\
\hline
\end{tabular}

For each female, reproductive states, which are determined by presence of calves and their age and whether they gave birth in the next year are shown. Females who gave birth in the following year, and females who were without calves were considered to be receptive at that time. Females who gave birth within ten months after the observation were considered to be pregnant at that time.

\section{Permutation test against non-random associations}

The $C V$ of the observed HWIs was higher than that of the random HWIs, indicating non-random associations among male dolphins (Table 1).

\section{Association criteria for possible alliance members}

There were ten pairs with HWIs higher than those expected by chance for multiple years, and most of these HWIs were reciprocally the highest for each male of the pairs and higher than the mean of the maximum HWI of males (Table 2). 




Fig. 2. A photograph showing a pair of males (\#0065 and \#0086) surrounding a female.

The associations between males of the possible alliance members and females

Of all photographs in which the males of the possible alliance members were identified, we confirmed 30 cases (one case refers to a series of events in a single sampling session) in which nine of the above-mentioned ten male pairs surrounded a female dolphin (Table 3, Fig. 2). In 17 of these 30 cases, females surrounded by male pairs were considered to be receptive at that time and eight females gave birth in the following year (Table 3 ).

\section{Discussion}

We were able to detect male pairs that satisfied our association criteria to identify possible alliance members and most of them were photographed surrounding females. Approximately half of the females that were surrounded by males were considered to be receptive at that time, and several of them gave birth in the following year. This suggests herding behavior or mate guarding by the male pairs. Connor et al. (1992) reported that males in pairs or triplets of alliance jointly herded females, and when traveling with a herded female, they were usually positioned on either side of and just behind the female or abreast behind her. The behavior in our photographs of the male pairs and females corresponded to these herding-like behaviors reported by Connor et al. (1992).

Our results strongly suggest the formation of alliances in Amakusa-Shimoshima population, as we expected based on the model by Whitehead and Connor (2005), which demonstrated that the likelihood of alliances is affected by the mean number of males competing for a female. Because of the large group size and the high sitefidelity to the small area, males in Amakusa-Shimoshima population likely face increased competition with a higher number of other males, and this probably contributes to the formation of alliances in this population.

Although most of the male pairs were photographed surrounding females, a couple of pairs were not (Pair C and F; Table 3). The reason why these male pairs were not photographed surrounding females might be insufficient data, because photographs in which more than one dolphins were photo-captured was limited.

For the same reason, we were not able to evaluate how much our methods bias the size of the detected alliances. Although the detected alliances in this study were in pairs, it is hard to say that males in Amakusa-Shimoshima population form alliance in pairs, not in triplets or more. Our association criteria for alliances were strict and this might bias the size of detected alliances. It is likely to happen that some of the alliance members were not photo-captured in the same picture even if three or more individuals form an alliance.

Our results lack detailed behavioral information such as aggressive herding behavior including chasing, biting, and slamming bodily into a female by these male pairs because it is difficult to keep following a specific pair of dolphins in a large group. Such detailed behavioral observations could further support for the apparent formation of alliances.

Further studies should focus on the patterns of alliances, such as alliance size and stability, for further understanding of alliance formation among dolphins.

Acknowledgments: We are grateful to Amakusa Dolphin Information for providing us boats to collect data. The manuscript was improved by the comments of two anonymous reviewers.

\section{References}

Balance, L. T. 1990. Residence patterns, group organization, and surfacing associations of bottlenose dolphins in Kino Bay, Gulf of California, Mexico. In (Leatherwood, S. and Reeves, R. R., eds.) The Bottlenose Dolphin, pp. 267-283. Academic Press, San Diego.

Cairns, S. J. and Schwager, S. J. 1987. A comparison of association indices. Animal Behaviour 35: 1454-1469.

Connor, R. C., Heithaus, M. R. and Barre, L. M. 2001. Complex social structure, alliance stability and mating access in a bottlenose dolphin "super-alliance". Proceedings of the Royal Society London B 268: 263-267.

Connor, R. C. and Krützen, M. 2015. Special issue: social evolution male dolphin alliances in Shark Bay: changing perspectives in a 
30-year study. Animal Behaviour 103: 223-235.

Connor, R. C., Richards, A. F., Smolker, R. A. and Mann, J. 1996. Patterns of female attractiveness in Indian Ocean bottlenose dolphins. Behaviour 133: 37-69.

Connor, R. C., Smolker, R. A. and Richards, A. F. 1992. Dolphin alliances and coalitions. In (Harcourt, A. H. and de Waal, F. B. M., eds.) Coalitions and Alliances in Animals and Humans, pp. 415443. Oxford University Press, Oxford.

Connor, R. C. and Whitehead, H. 2005. Alliances II. Rates of encounter during resource utilization: a general model of intrasexual alliance formation in fission-fusion societies. Animal Behaviour 69: 127132.

Elliser, C. R. and Herzing, D. L. 2014. Long-term social structure of a resident community of Atlantic spotted dolphins, Stenella frontalis, in the Bahamas 1991-2002. Marine Mammal Science 30: 308328.

Goodall, J. 1986. The Chimpanzees of Gombe: Patterns of Behaviour. Harvard University Press, Cambridge, 673 pp.

Inoue, K., Terashima, Y., Shirakihara, M. and Shirakihara, K. 2017. Habitat use by Indo-Pacific bottlenose dolphins (Tursiops aduncus) in Amakusa, Japan. Aquatic Mammals 43: 127-138.

Kogi, K., Hishii, T., Imamura, A., Iwatani, T. and Dudzinski, K. M. 2004. Demographic parameters of Indo-Pacific bottlenose dolphins (Tursiops aduncus) around Mikura Island, Japan. Marine Mammal Science 20: 510-526.

Lusseau, D. 2007. Why are male social relationships complex in the Doubtful Sound bottlenose dolphin population? PLOS ONE. DOI: 10.1371/journal.pone.0000348.

Möller, L. M., Beheregaray, L. B., Harcourt, R. G. and Krützen, M. 2001. Alliance membership and kinship in wild male bottlenose dolphins (Tursiops aduncus) of southeastern Australia. Proceedings of the Royal Society London B 268: 1941-1947.

Packer, C., Gilbert, D.A., Pusey, A. E. and O’Brien, S. J. 1991. A molecular genetic analysis of kinship and cooperation in African lions. Nature 351: 562-565.

Rogers, C. A., Brunnic, B. J., Herzing, D. L. and Baldw, J. D. 2004. The social structure of bottlenose dolphins, Tursiops truncatus, in the
Bahamas. Marine Mammal Science 20: 688-708.

Scott, M. D., Irvine, A. B. and Wells, R. S. 1990. A long-term study of bottlenose dolphins on the west coast of Florida. In (Leatherwood, S. and Reeves, R. R., eds.) The Bottlenose Dolphin, pp. 235-244. Academic Press, San Diego.

Shirakihara, M., Shirakihara, K., Tomonaga, J. and Takatsuki, M. 2002. A resident population of Indo-Pacific bottlenose dolphins (Tursiops aduncus) in Amakusa, western Kyushu, Japan. Marine Mammal Science 18: 30-41.

Smolker, R. A., Richards, A. F., Connor, R. C. and Pepper, J. W. 1992. Sex differences in patterns of association in Indo-Pacific bottlenose dolphins. Behaviour 123: 38-69.

Van Bressem, M-F., Shirakihara, M. and Amano, M. 2013. Cutaneous nodular disease in a small population of Indo-Pacific bottlenose dolphins, Tursiops aduncus, from Japan. Marine Mammal Science 29: 525-532.

Watts, D. P. 1998. Coalitionary mate guarding by male chimpanzees at Ngogo, Kibale National Park, Uganda. Behavioral Ecology 44: $43-55$.

Whitehead, H. 1990. Rules for roving males. Journal of Theoretical Biology 145: 355-368.

Whitehead, H. 1998. Male mating strategies: models of roving and residence. Ecological Modelling 111: 297-298.

Whitehead, H. 2009. SOCPROG programs: analyzing animal social structures. Behavioral Ecology and Sociobiology 63: 765-778.

Whitehead, H. and Connor, R. C. 2005. Alliances I. How large should alliances be? Animal Behaviour 69: 117-126.

Wilson, R. D. B. 1995. The Ecology of Bottlenose Dolphins in a Population at the Northern Extreme. Ph. D. Thesis, University of Aberdeen, Aberdeen, Scotland, 219 pp.

Wiszniewski, J., Brown, C. and Möller, L. M. 2012. Complex patterns of male alliance formation in a dolphin social network. Journal of Mammalogy 93: 239-250.

Received 2 November 2016. Accepted 10 May 2017. Editor was Mai Sakai. 